\title{
Successful twin pregnancy in panhypopituitarism
}

\author{
R D Jeewantha ${ }^{1}$, M R L Perera², C N Wijeyaratne ${ }^{2}$, L D Ranasinghe ${ }^{3}$ \\ Sri Lanka Journal of Diabetes, Endocrinology and Metabolism 2015; 5: 103-106
}

\begin{abstract}
Panhypopituitarism is characterized by inadequate or absent production of anterior pituitary hormones. This involves hypofunction of most of the major endocrine functions that affect fertility and reproduction. Deficiency of all six anterior pituitary hormones leads to deficiencies of gonadotrophins (FSH, LH), thyroid axis (TSH), adrenocortical hormones (ACTH), Growth Hormone $(\mathrm{GH})$ and Prolactin (PRL). GH and gonadotrophin deficiency are commoner (1) than TSH and ACTH deficiency (2).

Although pregnancy after complete loss of pituitary function is uncommon, advances in fertility treatment have led to increased pregnancy rates in these women. Problems related to pregnancy include infertility, lactation failure and increased risk of complications such as miscarriage, anaemia, pregnancy-induced hypertension, placental abruption, premature birth, and postpartum hemorrhage $(3,4,5)$. Conception in this group of patients usually requires the support of assisted reproductive techniques. Induction of ovulation by means of human or recombinant gonadotrophins is widely used in current practice. Progestrogen support following conception, optimizing other hormonal replacement and careful monitoring throughout pregnancy play a vital role in successful pregnancy outcomes. We report a subject with panhypopituitarism who was managed in our Endocrine Antenatal clinic with successful outcome.
\end{abstract}

Key words: panhypopitutarism, recombinant, gonadotrophins, antenatal clinic, fertility treatment.

\section{Case}

A 35 year old mother of one admitted from our antenatal clinic at 34 weeks of period of gestation for the tertiary care management of a dichorionic diamniotic (DCDA) twin pregnancy.

At the age of 20 years, she was diagnosed to have a Rathke's pouch cyst, which was surgically drained and followed by radiotherapy. Post-interventional panhypopituitarism was diagnosed and she was on hormone replacement for hypocortisolism, hypothyroidism and hypopogonadotropic hypogonadism; while growth hormone was not replaced due to lack of funding. She was replaced with oral levo-thyroxine, hydrocortisone (20mg daily in split doses) and the combined oral contraceptive pill (OCP). The patient remained symptomfree and returned to full time work. Upon her request, at the age of 28 years as fertility treatment, induction of ovulation with gonadotrophins was done. During the second cycle of treatment with recombinant FSH for follicular development and maturation with subsequent human chorionic gonadotrophin (hCG) for ovulation following ultrasound ovum tracking coupled, with Intra Uterine Insemination (IUI) resulted in a singleton intrauterine pregnancy.
Her first pregnancy was otherwise uncomplicated apart from the diagnosis of Gestational Diabetes Mellitus (GDM) at 28 weeks gestation, which was managed only by dietary modifications. She gave birth to a healthy male baby at term weighing $3.6 \mathrm{~kg}\left(90^{\text {th }}\right.$ centile $)$ by an elective Lower Segment Caesarean Section (LSCS) on her request.

At the age of 34 years, she requested fertility treatment for her second pregnancy. After failure of initial ovulation induction by recombinant FSH treatment, which ended up with a blighted ovum, she was commenced on Human Menopausal Gonadotrophins (hMG). Ovulation induction with hMG was initiated at a daily dose of 75 units, which was increased to 150 units daily after 15 days. The increased dose was continued for a further 10 days with a total duration of 25 days. When the dominant follicle was beyond $18 \mathrm{~mm}$, hCG 5000 IU was administered intramuscularly. Subsequently, she underwent IUI, which resulted in conception and she was given luteal phase support with vaginal progesterone until 12 weeks of gestation. Assessment of adequacy of hormone replacement was confirmed biochemically with serial cortisol levels as a 'day curve' while on oral hydrocortisone, free thyroxine along with glucose, renal, hepatic and electrolyte evaluations. The hydrocortisone dose was

${ }^{1}$ Professorial obstetrics and gynaecology unit, De Zoysa maternity hospital, Colombo, ${ }^{2}$ Department of obstetrics and gynaecology, Faculty of medicine, university of Colombo, ${ }^{3}$ National hospital of SriLanka. 
increased to $25 \mathrm{mg}$ per day ( $10 \mathrm{mg}$ mane and $5 \mathrm{mg}$ at midday and vesper) from 8 weeks of gestation and maintained up to delivery with repeat 'day curves'. Thyroxine dose was increased to $125 \mu \mathrm{g}$ daily in the first trimester and later in third trimester to $150 \mu \mathrm{g}$ daily to maintain a high normal free thyroxin concentration $(>1.5 \mathrm{ng} / \mathrm{dl})$.

A Dichorionic Diamniotic (DCDA) twin pregnancy was confirmed by the dating ultrasound scan at 8 weeks gestation. Diabetes mellitus was diagnosed at 8 weeks of gestation by a high $2^{\text {nd }}$ hour $75 \mathrm{~g}$ oral glucose challenge test of $158 \mathrm{mg} / \mathrm{dl}(>140 \mathrm{mg} / \mathrm{dl})$ and $\mathrm{HbA}_{1} \mathrm{C}$ level of $7.4 \%$ that raised the possibility of pre-existing diabetes. Therefore, renal, eye and cardiovascular assessments were done in order to screening for end organ damage. Patient was initialy management with lifestyle interventions and with metformin 500mg twice daily. Later at 28 weeks gestation, pre-mixed 30/70 Human Insulin 4 IU twice daily was added and continued until delivery to attain good glycaemic control.

Fetal growth was monitored using regular ultrasound scans and showed normal growth without any fetal anomalies. During late third trimester, she presented with persistently low Haemoglobin $(9.4 \mathrm{~g} / \mathrm{dl})$ which was further investigated and confirmed as iron deficiency anaemia. The condition was managed with Ferrous sulphate daily with the target of achieving $\mathrm{Hb}>10 \mathrm{~g} / \mathrm{dl}$ at the time of delivery.

She gave birth to healthy male twins with birth weights of $2.18 \mathrm{~kg}\left(10^{\text {th }}-50^{\text {th }}\right.$ centile $)$ and $2.65 \mathrm{~kg}\left(50^{\text {th }}-90^{\text {th }}\right.$ centile) respectively in $\mathrm{T} 1$ and $\mathrm{T} 2$ twins at 36 weeks of GA by elective LSCS under epidural anaesthesia. A single stress-dose of hydrocortisone (100mg) intravenously was administered pre- epidural insertion and tapered to the maintenance level of 50mg three times per day for the first 48 hours. Lactation failure occurred following delivery as expected in a patient with panhypopituitarism, that required artificial milk feeds.

Neonatal adaptation was unremarkable with normal growth parameters. Both babies and mother were discharged on postpartum day 8 . The mother discharged on pre-pregnant homone replacement doses.

\section{Discussion}

The patients with panhypopituitarism should be replaced with deficient anterior pituitary hormones this hormonal substitution should be initiated in an orderly manner, which include glucocorticoid, thyroid hormone, sex hormone, and growth hormone respectively. In general, the thyroid hormone replacement is initiated two weeks after glucocorticoid replacement, commencing at a low dosage in order to prevent an Addisonian crisis (6). However, as thyroxine takes approximately two weeks to show the maximum metabolic benefit, both thyroxin and hydrocortisone can be commenced concurrently under close supervision in patients with hypocortisolism.

Although natural pregnancy is uncommon in such patients, modern advances in assisted reproductive techniques and careful monitoring throughout pregnancy has enabled successful outcomes. Pre pregnancy preparation with appropriate adjustment in hormonal level plays a vital role in achieving this.

Approximately one third of maternal thyroid hormone is delivered to the fetus, which is crucial for fetal neurodevelopment in the first half of pregnancy prior to fetal pituitary-thyroid axis development (1). It has shown that perinatal thyroid dysfunction can lead to a significant reduction in body weight and height, delayed neurodevelopment, high risk of cognitive disorders and depression-like behaviors in infants (7). The evidence suggests an association between gestational hypopituitarism and impaired intellectual and cognitive development in offspring (8) and irreversible damage to the auditory system functions caused by perinatal hypothyroidism in rats (9). Considering this vital role played by maternal thyroid hormones on fetal neurodevelopment, our patient's first trimester thyroxine dose was increased from $100 \mu \mathrm{g}$ daily pre-conception to $125 \mu \mathrm{g}$ daily and later in the third trimester to $150 \mu \mathrm{g}$ daily to maintain a high normal free thyroxin concentration $(>1.5 \mathrm{ng} / \mathrm{dl})$.

During pregnancy, both total and free plasma cortisol concentration increases during gestation and upto 2- to 3 -fold elevation of plasma cortisol values can occur during the third trimester when compared with non-pregnant controls. In some patients, these values could reach as high as to the values in the range seen in Cushing's syndrome $(10,11)$. This may be due to the antiglucocorticoid effects of elevated progesterone levels during pregnancy (12). Placental CRH appears to be the primary stimulus for cortisol production especially during third trimester. However, due to the placental 11- $\beta$ hydroxysteroid dehydrogenase-2, which inactivates active glucocorticoids, the fetus is protected from the effects of maternal hypercortisolism as well as exogenous steroids such as hydrocortisone $(13,14)$. On the other hand, synthetic long-acting glucocorticoids such as dexamethasone should be avoided in pregnancy as it can cross the placental barrier unaltered.

Because of the gradual increase in free cortisol observed during pregnancy, it may be required to increase the hydrocortisone dose by $50 \%$ during the last trimester of pregnancy. Stress doses of hydrocortisone should be given for LSCS, which can be tapered over $48 \mathrm{~h}$ to a regular replacement dose (1). Our patient received an increased hydrocortisone dose of $25 \mathrm{mg}$ per day $(10 \mathrm{mg}$ mane and midday, $5 \mathrm{mg}$ vesper) from 8 weeks of gestation up to delivery, in comparison with $15 \mathrm{mg}$ daily (10mg mane and 
$5 \mathrm{mg}$ vesper) pre-conception. In addition to that, she was given a single stress-dose of hydrocortisone (100mg) in preparation for LSCS followed by intravenous hydrocortisone to cover the stress in the first 48 hours.

The evidence suggests that GH treatment reduces the abortion rate in patients with $\mathrm{GH}$ deficiency and $\mathrm{GH}$ replacement during early pregnancy has shown to be of some benefit $(15,16)$. However in these patients, isolated GH deficiency is unlikely to be a main contributory factor for poor pregnancy outcomes as placental GH can compensate for its action during gestation. Although our patient was GH deficient, she was never given GH replacement due to fund constraints. Further her first successful pregnancy without replacement supported our care plan of not giving $\mathrm{GH}$ for the current pregnancy as well.

PRL deficiency is common in panhypopituitary patients and cause problems due to insufficient breast milk production (18). A retrospective study based on 18 pregnancies in 9 hypopituitary patients has shown that only one patient could breastfeed her baby (19). The same result was observed in our patient who presented with lactation failure due to insufficient breast milk production. Currently, there is no effective medication available to treat prolactin deficiency and generally formula milk is recomended. However, a pilot study has shown that twice daily r-hPRL replacement increases milk volume in mothers with prolactin deficiency and also in preterm mothers with lactation insufficiency (20).

Human gonadotrophins either urinary or recombinant are used for ovulation induction in panhypopituitary patients. In patients with central hypogonadism following hypopituitarism, HMG is preferred over recombinant FSH as it contains both FSH and LH, which is needed in the latter part of follicular phase apart from FSH for the final maturation of follicles (18). In general, these patients need higher doses of gonadotrophins and longer duration of treatment since they are lacking endogenous gonadotrophins (18). Our patient received $150 \mathrm{IU}$ of HMG for 25 days and achieved optimum follicular maturation $(>18 \mathrm{~mm})$ and a succesful pregnancy, after an initial attempt with recombinant FSH which ended up in an early first trimester miscarriage.

It is an established fact that follicular growth and probable pregnancy rate improves when GH and HMGHCG are combined for ovulation induction in hypogonadotropic patients (21). It also increases the IGF1 and IGF2 activity in the ovary thus enhances follicular stimulation (22). Although our patient wasn't treated with GH, she received HMG and $\mathrm{HCG}$ combination with successful conception.

Following implantation, placenta starts to function as a very efficient endocrine organ and produces a variety of peptide hormones produced by the pituitaryhypothalamus including gonadotrophin releasing hormone $(\mathrm{GnRH})$ and chorionic gonadotrophin, which is structurally and functionally similar to LH. It also produces significant quantities of estrogens and progesterone, which are also produced by the ovary. Thus the placenta acts as a transient hypothalamo-pituitary-gonadal axis during pregnancy that efficiently overcomes the endocrine problem at hand $(23,24)$.

Multiple pregnancies are a known complication of ovulation induction (25). However, when considering high risk pregnancies in patients with hypopituitarism, it has been suggested that fertility treatment must strive for singleton pregnancies with application of particular strict criteria to avoid multiple pregnancies (26). Above all, it can be deduced that women with prolonged central hypogonadism have a greater risk of uterine defects following hormonal deficiency, that can add to the complications of twin pregnancy. An audit carried out in a single center concerning outcomes of 18 pregnancies in 9 women with hypopituitaarism who underwent ovulation induction has shown a live birth rate of $61 \%$ with no survivors from 4 sets of twins (26). This hightlights how rare the occurrence of a successful twin delivery in patients with hypopituitarism.

There seem to be an association between hypothyroidism and iron deficiency anaemia (IDA) and it is thought to be due to deficiency of thyrotrophic and adrenotrophic hormones (27). Therefore, optimum hormone replacement plays a vital role in preventing IDA and normochromic normocytic anemia in these patients with hypopituitarism, which is a essential for a succesful pregnancy.

\section{Conclusions}

Even though the pregnancy after complete loss of pituitary function is uncommon, modern advances in fertility treatment has led to increased pregnancy rates in women with panhypopituitarism. However, preconceptional restoration of hormones, close careful monitoring and changing medications throughout pregnancy plays a vital role in successful outcomes in view of both fetal and maternal wellbeing.

\section{References}

1. Karaca Z, Tanriverdi F, Unluhizarci K, Kelestimur F. Pregnancy and pituitary disorders. Eur J Endocrinol 2010; 162: 453-75.

2. Dong AM, Yin HF, Gao YM, Guo XH. Spontaneous pregnancy in a patient with lymphocytic hypophysitis. Beijing Da ХиеХиеBao 2009; 41: 242-44.

3. Kübler K, Klingmüller D, Gembruch U, Merz WM. Highrisk pregnancy management in women with hypopituitarism. J Perinatol 2009; 29: 89-95. 
4. Overton CE, Davis CJ, West C, Davies MC, Conway GS. High risk pregnancies in hypopituitary women. Hum Reprod 2002; 17: 1464-7.

5. Davis LE, Leveno KJ, Cunningham FG. Hypothyroidism complicating pregnancy. Obstet Gynecol 1988; 72: 108-12.

6. Xue Du, Qing Yuan, Yanni Yao, Zengyan Li, Huiying Zhang. Hypopituitarism and successful pregnancy. Int J Clin Exp Med 2014; 7(12): 4660-5.

7. Lazarus JH. Thyroid disease in pregnancy and childhood. Minerva Endocrinol 2005; 30: 71-87.

8. Alexander EK, Marqusee E, Lawrence J, Jarolim P, Fischer GA, Larsen PR. Timing and magnitude of increases in levothyroxine requirements during pregnancy in women with hypothyroidism. $N$ Engl J Med 2004; 351: 241-49.

9. Wada H, Yumoto S, Iso H. Irreversible damage to auditory system functions caused by perinatal hypothyroidism in rats. Neurotoxicol Teratol 2013; 37: 18-22.

10. Demey-Ponsart E, Foidart JM, Sulon J, Sodoyez JC. Serum CBG, free and total cortisol and circadian patterns of adrenal function in normal pregnancy. J Steroid Biochem 1982; 16(2): $165-9$.

11. Odagiri E, Ishiwatari N, Abe $\mathrm{Y}$, et al. Hypercortisolism and the resistance to dexamethasone suppression during gestation. Endocrinol Jpn 1988; 35: 685-90.

12. Allolio B, Hoffmann J, Linton EA, Winkelmann W, Kusche M, Schulte HM. Diurnal salivary cortisol patterns during pregnancy and after delivery: relationship to plasma corticotrophin releasing hormone. Clin Endocrinol (Oxf) 1990; 33: 279-89.

13. Fowden AL, Forhead AJ. Endocrine mechanisms of intrauterine programming. Reproduction 2004; 127: 515 526.

14. Seckl JR, Cleasby M, Nyirenda MJ. Glucocorticoids, $11 \beta$ hydroxysteroid dehydrogenase, and fetal programming. Kidney Int 2000; 57: 1412-17.

15. Sakai S, Wakasugi T, Yagi K, Ohnishi A, Ito N, Takeda Y, Yamagishi M. Successful pregnancy and delivery in a patient with adult GH deficiency: role of GH replacement therapy. Endocr J 2011; 58: 65-8.

16. Müller J, Starup J, Christiansen JS, Jørgensen JO, Juul A, Skakkebaek NE. Growth hormone treatment during pregnancy in a growth hormone-deficient woman. Eur $J$ Endocrinol 1995; 132: 727-279.
17. Wang YF, Yang HX. Clinical analysis of hypothyroidism during pregnancy. Zhonghua Fu Chan Ke Za Zhi 2007; 42: 157-60.

18. Thomas VP, Sathya B, George S, Thomas N. Pregnancy in a patient with hypopituitarism following surgery and radiation for a pituitary adenoma. $J$ Postgrad Med 2005; 51: 223-4.

19. Overton CE, Davis CJ, West C, Davies MC, Conway GS. High risk pregnancies in hypopituitary women. Hum Reprod 2002; 17: 1464-7.

20. Powe CE, Allen M, Puopolo KM, Merewood A, Worden $\mathrm{S}$, Johnson LC, et al. Recombinant human prolactin for the treatment of lactation insufficiency. Clin Endocrinol $(O x f)$ 2010; 73(5): 645-53.

21. Homburg R, West C, Torresani T, Jacobs HS. Cotreatment with human growth hormone and gonadotropins for induction of ovulation: a controlled clinical trial. Fertil Steril 1990; 53(2): 254-60.

22. Salle A1, Klein M, Pascal-Vigneron V, Dousset B, Leclere J, Weryha G. Successful pregnancy and birth after sequential cotreatment with growth hormone and gonadotropins in a woman with panhypopituitarism: a new treatment protocol. Fertil Steril 2000; 74(6): 1248-50.

23. Sumana Santra, Y. Gopi Shanker, A. Jagannadha Rao. Regulation of Endocrine Function in Human Placenta - Is it similar to hypothalamo-pituitary-gonadal axis? Reproductive Immunology 1999; 187.

24. Kelly AC, Rodgers A, Dong KW, Barrezueta NX, Blum M, Roberts JL. Gonadotropin-releasing hormone and chorionic gonadotropin gene expression in human placental development. DNA Cell Biol 1991; 10(6): 411-21.

25. Schenker JG, Yarkoni S, Granat M. Multiple pregnancies following induction of ovulation. Fertil Steril 1981; 35(2): 105-23.

26. Caroline C. Overton, Colin J. Davis, Christine West, Melanie C. Davies, Gerard S. Convey. High risk pregnancies in hypopituitary women. Human reprod 2002: 17(6): 1464-7.

27. R King, Mizban N and Rajeswaran C. Iron deficiency anaemia due to hypopituitarism. Endocrine Abstracts 2009; 19: 278.

28. Nishioka H1, Haraoka J. Hypopituitarism and anemia: effect of replacement therapy with hydrocortisone and/or levothyroxine. J Endocrinol Invest 2005; 28(6): 528-33. 